\title{
FOSSILDIAGÊNESE DE LENHOS DO MESOZÓICO DO ESTADO DO RIO GRANDE DO SUL, BRASIL
}

\author{
ROBSONTADEU BOLZON \\ Departamento de Geologia, SCT, UFPR, Cx. P. 19001, 81531-970, Curitiba, PR, Brasil. bolzonrt@ufpr.br \\ JOSÉLUIZ SILVÉRIODASILVA \\ Departamento de Geociências, CCNE, UFSM, 97119-900, Santa Maria, RS, Brasil. silverio@base.ufsm.br \\ LUCIANO GANDIN MACHADO \\ Curso de Ciências Biológicas, UFPR, Cx. P. 19001, 81531-970, Curitiba, PR. Brasil. l_machado@bol.com.br
}

\begin{abstract}
RESUMO - Neste trabalho será apresentado um modelo relacionando alguns processos diagenéticos com a preservação das células de lenhos fósseis do Mesozóico do Estado do Rio Grande do Sul, considerando que: (a) os processos diagenéticos podem destruir ou preservar os lenhos fósseis; (b) o processo de mineralização dos caules depende dos componentes das paredes celulares e das características do ambiente deposicional; e (c) a silicificação do lenho é um importante processo de preservação. Os caules silicificados são encontrados em arenitos fluviais de idade incerta (Triássico final ou Jurássico) ou expostos pela erosão e espalhados amplamente na área de estudo. A estrutura dos lenhos foi analisada em microscopia ótica e eletrônica de varredura. A identificação da mineralogia foi acompanhada da análise de difração de raios-x. O modelo apresenta quatro estágios: (i) destruição do tecido lenhoso anterior à infiltração e precipitação de minerais; (ii) início da infiltração de minerais com precipitação e nucleação no lúmen celular a partir da superfície das paredes celulares; (iii) alterações na parede celular com a degradação de elementos orgânicos residuais; e (iv) preenchimento e/ou precipitação de minerais a partir da superfície dos lumens celulares.
\end{abstract}

Palavras-chave: lenhos fósseis, Mesozóico, preservação, Rio Grande do Sul.

ABSTRACT - WOOD FOSSIL DIAGENESIS IN MESOZOIC ROCKS FROM THE RIO GRANDE DO SUL STATE, BRAZIL. This paper presents a model relating some processes diagenetics with the preservation of the cells of fossil wood of Mesozoic of Rio Grande do Sul State, considering that (a) diagenesis serves to both destroy and preserve wood fossils; (b) the form of wood mineralization is dependent on the components of cell walls and depositional environment; and (c) silicification of wood is an important means of preservation. Silicified wood are found in fluvial sandstones of uncertain age (Upper Triassic or Jurassic) or exposed by erosion and widely scattered over the studied area. The wood structure was analyzed by optic microscope and scanning electron microscope. In order to determinate the mineralogy sample was submitted to XRD. The model presents four stages: (i) wood tissue decay before mineralization; (ii) minerals precipitation in lumen along cellular surfaces; (iii) degradation of organic components of the cell walls; and (iv) deposition of silica along lumen surface in void space created.

Key words: wood fossil, Mesozoic, preservation, Rio Grande do Sul.

\section{INTRODUÇÃO}

Os caules silicificados do Mesozóico do Estado do Rio Grande do Sul ocorrem em uma faixa leste-oeste de, aproximadamente, $200 \mathrm{~km}$ na depressão central, embora o registro mais expressivo esteja nos municípios de São Pedro do Sul, Mata e Santa Maria (Bolzon \& Guerra-Sommer, 1994). A maioria dos exemplares ocorre dispersa pela área, recobrindo depósitos de idades variadas. Os lenhos analisados que foram encontrados inclusos em arenitos estariam relacionados às sequiências Ladiniana-Eonorina e Rética, reconhecidas por Scherer et al.(2000).
Estudos anteriores sobre a tafonomia (Bolzon \& GuerraSommer, 1994), a mineralogia (Guerra-Sommer \& Gamermann, 1985; Silvério da Silva, 1997), e a preservação das estruturas celulares (Silvério da Silva et al., 1997; Silvério da Silva \& Bolzon, 1997; Bolzon \& Machado, 2002) demonstraram uma grande variabilidade na preservação do tecido lenhoso e que a sílica é o principal elemento do processo de mineralização. Bolzon \& Machado (2002) ao quantificar a preservação celular do xilema secundário de caules de coníferas, dividiram os traqueóides e as células de parênquima radial em várias categorias de preservação (Tabela 1).

O objetivo deste trabalho é apresentar um modelo relacio- 
Tabela 1. Categorias de preservação das células do xilema secundário (modificado de Bolzon \& Machado, 2002). Table 1. Categories of the wood cells preservation (modified of Bolzon \& Machado, 2002).

\begin{tabular}{|c|c|c|c|}
\hline & & CATECORIA & CARACTERISTICAS \\
\hline \multirow{10}{*}{$\begin{array}{l}0 \\
0 \\
0 \\
0 \\
11\end{array}$} & \multirow{6}{*}{ 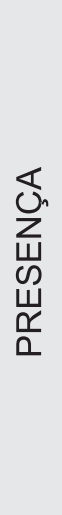 } & parede e lúmen & parede bem definida e lúmen preenchido \\
\hline & & lúmen & $\begin{array}{l}\text { a parede se confunde com a das células adjacentes mas com o lúmen bem } \\
\text { definido }\end{array}$ \\
\hline & & parede & bem definida e o interior da célula vazio, não mineralizado \\
\hline & & fantasma & $\begin{array}{l}\text { não é possível definir a parede e o lúmen, o limite da parede é inferido, mas não } \\
\text { delimitado }\end{array}$ \\
\hline & & raios & observação ou não de suas células com a parede e o lúmen \\
\hline & & células torcidas & todas as categorias anteriores com células compactadas e forma modificada \\
\hline & \multirow{4}{*}{ 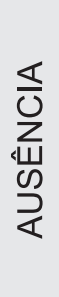 } & amorfa & a mineralização destruiu as estruturas celulares e ocorrem minerais \\
\hline & & vazio & $\begin{array}{l}\text { reflete a porosidade, fraturas não preenchidas e regiões sem tecidos ou cujo tecido } \\
\text { foi destruído }\end{array}$ \\
\hline & & cristais & com megacristais de quartzo \\
\hline & & fraturas & regiões rompidas e preenchidas por minerais \\
\hline
\end{tabular}

nando os prováveis processos diagenéticos com as categorias de preservação das células axiais (traqueóides) e das células de parênquima radial.

\section{MATERIAL E MÉTODOS}

As amostras analisadas representam caules de Coniferophyta (senso Taylor \& Taylor, 1993) que foram coletados em afloramentos localizados nos municípios de Santiago, Mata, São Pedro do Sul, Santa Maria, Restinga Seca, Faxinal do Soturno e Santa Cruz do Sul. Todas as amostras foram observadas em microscópio estereoscópico (MOE). A análise incluiu também a observação em microscopia ótica de luz transmitida (MOT) e microscopia eletrônica de varredura (MEV) de secções de caules expostas, quebradas e cortadas com disco diamantado. A identificação da mineralogia foi acompanhada da análise de lâminas petrográficas e de difração de raios-X.

$\mathrm{O}$ fato de grande parte dos caules serem encontrados rolados dificulta o exato posicionamento estratigráfico de todas as amostras. Conforme Scherer et al. (2000), o Mesozóico do Rio Grande do Sul está representado por cinco seqüências: Eoscytiana, Ladiniana-Eonoriana, Rética, Neojurássica e Neocomiana. Assim, considerando as características litológicas e a distribuição geográfica das unidades, verifica-se que na região de Faxinal do Soturno, Restinga Seca e Santa Cruz do Sul, os caules estariam na Seqüência Ladiniana-Eonorina. Entre os municípios de Santa Maria e Jaguari, incluindo São Pedro do Sul, Mata e Santiago, os caules são registrados em depósi- tos fluviais da Sequiência Rética, que equivale litoestratigraficamente, ao Arenito Mata de Faccini (1989).

As ilustrações (fotomicrografias) apresentadas neste trabalho são de quatro exemplares. A amostra PB-788 UFRGS e 1045 (Museu Guido Borgomanero) constituem parte do mesmo exemplar e foi coletada durante a abertura de uma estrada no Município de Mata. As demais amostras foram encontradas inclusas em arenitos, duas (Pb-067 e Pb-030) em São Pedro do Sul (coordenadas 29³8'259S/54²10'817W) e uma (PB-037) na rodovia para Faxinal do Soturno (coordenadas 2942'494S/53³0'105W). As amostras estão depositadas na Coleção de Paleobotânica (Laboratório de Paleobotânica), Departamento de Geologia/SCT-UFPR (Pb-030, 037 e 067), na Coleção de Paleobotânica do Departamento de Paleontologia e Estratigrafia/IG-UFRGS (Pb-788) e Museu Guido Borgomanero da Cidade de Mata - RS (n. 1045).

\section{PROCESSOS FOSSILDIAGENÉTICOS}

Os processos fossildiagenéticos dos tecidos lenhosos estão relacionados com a sua estrutura e composição química e com as características do ambiente deposicional, que interagem com variáveis climáticas, hidrológicas, geoquímicas e biológicas, além da granulometria, da porosidade, do $\mathrm{pH}$, do $\mathrm{pCO}_{2}$ e das reações de óxi-redução (Eh).

Segundo Bolzon \& Guerra-Sommer (1994), todos os trabalhos referentes aos níveis com caules silicificados do Mesozóico do Rio Grande do Sul são unânimes em concluir que a deposição dos mesmos estaria relacionada a um ambi- 
ente fluvial. Os caules inclusos em arenitos avermelhados de origem fluvial predominam em fácies de arenitos grosseiros a conglomeráticos, ocorrendo, secundariamente, em fácies de arenitos médios a finos, ambos apresentando intraclastos argilosos intraformacionais com diâmetros de até $10 \mathrm{~cm}$ (Bolzon et al., 1994, Silvério da Silva, 1997).

A estrutura do lenho das Coniferophyta é relativamente homogênea, sendo composta por dois sistemas de células, um orientado longitudinalmente e outro, radialmente (raios). O sistema longitudinal ou axial é constituído por aproximadamente $90 \%$ de traqueóides. As paredes das células de lenho (p. ex., os traqueóides), são estruturadas em três partes fundamentais: a lamela média, a parede primária e a parede secundária. A parede secundária apresenta três camadas com características físicas e químicas diferentes. Os principais componentes da parede celular são a celulose, a hemicelulose e a lignina. É na parede secundária que ocorre a maior concentração de lignina (Morey, 1980). A lamela média é rica em lignina e elementos pécticos e pobre em celulose (Meylan \& Butterfield, 1972). As células de lenho inicial, ou seja, as que se desenvolvem no início da estação de crescimento, apresentam parede mais delgada que as de lenho tardio, que são as formadas ao final da estação de crescimento.

Os processos fossildiagenéticos associados aos lenhos do Mesozóico do Rio Grande do Sul promoveram a destruição e/ou a preservação das estruturas celulares. $\mathrm{O}$ modelo aqui proposto inclui quatro estágios principais: (i) destruição do tecido lenhoso anterior à infiltração e à precipitação de minerais; (ii) início da infiltração de minerais com precipitação e nucleação no lúmen celular, a partir da superfície das paredes celulares; (iii) alterações na parede celular com a degradação de elementos orgânicos residuais; e (iv) preenchimento e/ou precipitação de minerais, a partir da superfície dos lumens celulares.

\section{Destruição do tecido lenhoso anterior à infiltração e precipitação de minerais}

Os processos relacionados a esta etapa resultaram em células com paredes afastadas, células comprimidas e células com paredes rompidas (Figura 1). As células com paredes rompidas e as células comprimidas podem ser observados em microscópio estereoscópico, em lâminas delgadas (Figura 2A,B) e microscopia eletrônica de varredura (Figura 2C). Quando observadas macroscopicamente, as regiões onde as células estão rompidas ou comprimidas tangencialmente sugerem aparentes limites de anéis de crescimento (Bolzon \& Marchiori, 1993).

Em ambiente anóxicos, os processos de destruição do tecido lenhoso estão relacionados à ação de bactérias. Kim \& Singh (2000) discutiram as diferentes formas de decomposição por bactérias reconhecidas em madeiras. Na erosão bacteriana, as bactérias degradam componentes não lignificados da parede celular, produzindo sulcos. As diferenças na composição química existente nas paredes celulares podem refletir em lumens inflados, separação das paredes, destruição desigual e, usualmente, podem restar apenas as lamelas médias de células adjacentes (Schweingruber, 1982). A ação microbial também ocasiona mudanças das propriedades físicas e mecânicas (Obst et al., 1991). A compactação resultante de forças horizontais devido à carga do sedimento sobrejacente promove a compressão das células e, em alguns casos, o rompimento das paredes celulares. Este processo ocorre, inicialmente, nas células de lenho tardio e estaria associado à manutenção das pontoações abertas, ao contrário do lenho inicial, onde ocorre aspiração das pontoações.

A destruição do tecido lenhoso não ocorre de maneira contínua, mas em mosaicos. Durante este estágio, as células ficam altamente alteradas, inchadas, ou resta apenas a lamela média.
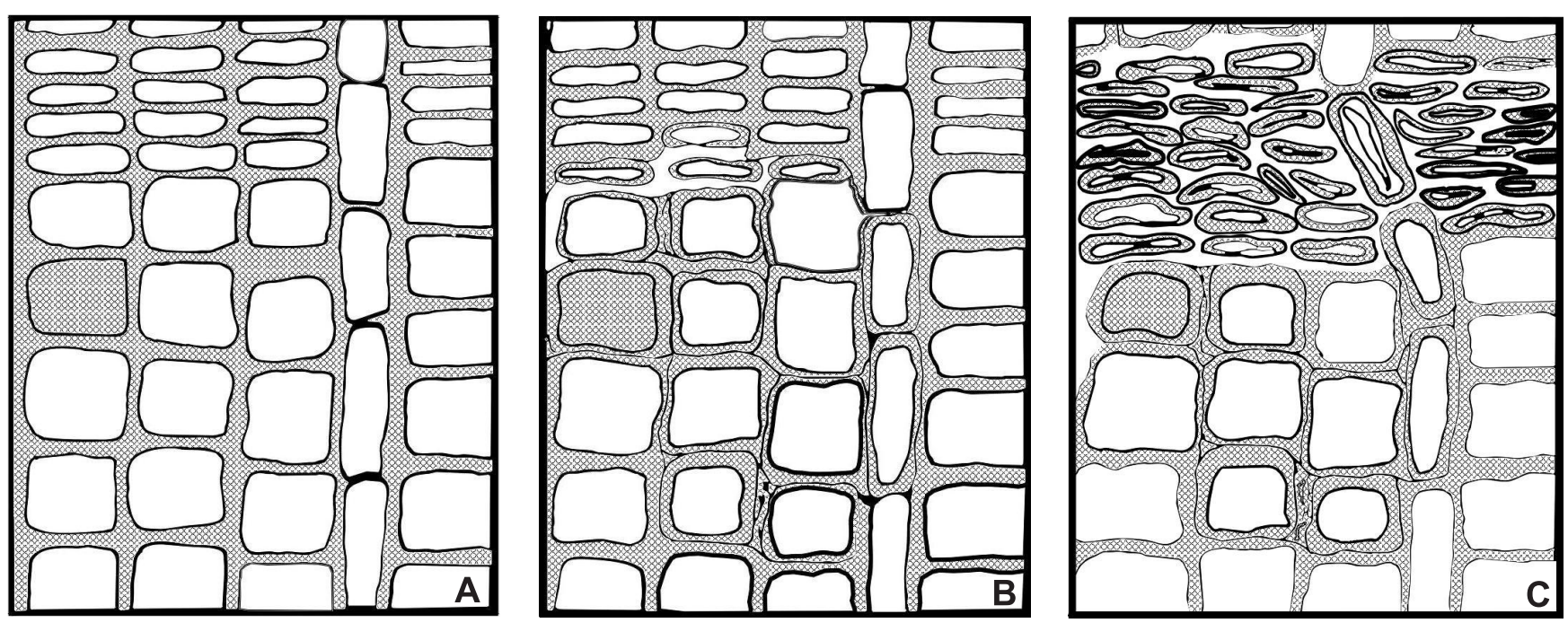

Figura 1. Secção transversal de um lenho de conífera ilustrando a degradação das paredes celulares no estágio 1: A. Lumens inflados, separação das paredes e destruição desigual dos constituintes celulares; B, C. Perda da rigidez das paredes celulares e início da compactação das células, especialmente de lenho tardio (ver legenda na Figura 7).

Figure 1. Cross-section of a conifer wood showing the cellular wall degradation in stage 1: A. Inflated lumens, separation of the walls, and unequal destruction of the cellular walls; B, C. Lost of the cellular wall rigidity and beginning of the cells compression, especially in latewood (see legend in the Figure 7). 

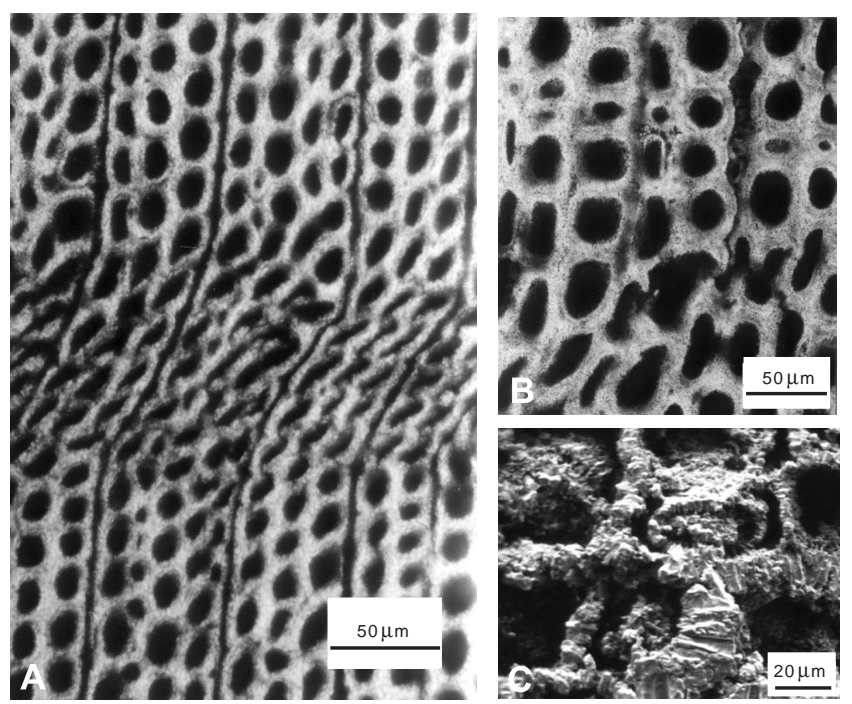

Figura 2. Secções transversais (amostra $\mathrm{Pb}-788$ ) evidenciando a destruição do lenho relacionada ao estágio 1: A. Células com paredes afastadas (MOT); B, C. Células com paredes comprimidas e rompidas (MEV).

Figure 2. Cross-sections (sample $\mathrm{Pb}$-788) showing the wood destruction in stage 1: A. Cells with walls moved away (TOM transmission optical microscopic); B, C. Cells with compressed and torn walls (SEM).

Início da infiltração de minerais com precipitação e nucleação no lúmen celular a partir da superfície das paredes celulares

A entrada e a precipitação de minerais são processos contemporâneos e interdependentes do estágio anterior (Figura 3). As evidências deste estágio (Figura 4) incluem as células em que os lumens não foram preenchidos. Em microscópio estereoscópico (Figura 4A), é possível observar que a célula não foi preenchida, enquanto que os detalhes da mineralogia da parede são observados em microscopia eletrônica de varredura (Figura 4C,D). É nesta etapa que ocorre a preservação da maioria das estruturas celulares (Figura 4B).

O processo de mineralização da madeira recebe diferentes denominações. Schopf (1975), em seu trabalho clássico sobre modos de fossilização, discutiu o uso dos termos "permineralização" e "petrificação". Mussa \& Coimbra (1984), utilizaram os termos "substituição", "recristalização", "preenchimento complementar" e "intraincrustação". Os termos utilizados representam as diferentes concepções dos autores, e adotar uma terminologia implicaria em concordar com o entendimento do autor para o processo de mineralização da madeira (Bolzon, 1993). Por exemplo, as células com lumens não preenchidos indicam o processo de "substituição" senso Mussa \& Coimbra (1984), mas não seria um processo de "permineralização" senso Schopf (1975), que incluiria as células com parede celular preservada e lúmen preenchido. Após os trabalhos de Leo \& Barghoorn (1976) e Sigleo (1978, 1979), existe uma tendência em considerar o processo de silicificação como a "impermeabilização" ou o "preenchimento de cavidades". A entrada e a precipitação de sílica nas paredes das células ocorrem por processos físicos-químicos e bioquímicos determinados pela união de pontes de hidrogê- nio que se formam entre os grupos hidroxílicos do ácido silícico e os radicais livres da matéria orgânica parcialmente degradada (Leo \& Barghoorn, 1976; Sigleo, 1978). Leo \& Barghoorn (1976) propuseram que a decomposição parcial é necessária, mas pode ser insignificante, do ponto de vista morfológico. A preservação dos fragmentos ocorre muitas vezes da superfície externa para o interior, onde a precipitação de sílica se inicia com a polimeralização e desidratação do ácido silícico. As partes internas são progressivamente mineralizadas e a decomposição pode destruir os tecidos sendo as cavidades resultantes preenchidas por sílica.

A preservação das estruturas da madeira é atribuída, em grande parte, ao tipo de textura cristalina que está presente (Mussa \& Coimbra, 1984). Os tipos ou texturas da sílica que ocorrem em lenhos silicificados são os mesmos formados em rochas sedimentares. Conforme Carson (1991), o quartzo e a opala constituem inicialmente os dois tipos de sílica encontrados em rochas sedimentares. Com base na petrografia, o quartzo pode ser dividido em megaquartzo, com cristais maiores que $20 \mu \mathrm{m}$ e, quando menores, em microquartzo. O microquartzo pode ser ainda microcristalino (grãos com diâmetro de 1-4 $\mu \mathrm{m}$ ) e a calcedônia (com cristais de natureza fibrosa). A opala pode ser reconhecida por difração de raiosx em: opala-C, opala-A, opala-CT e tridimita desordenada. $\mathrm{Na}$

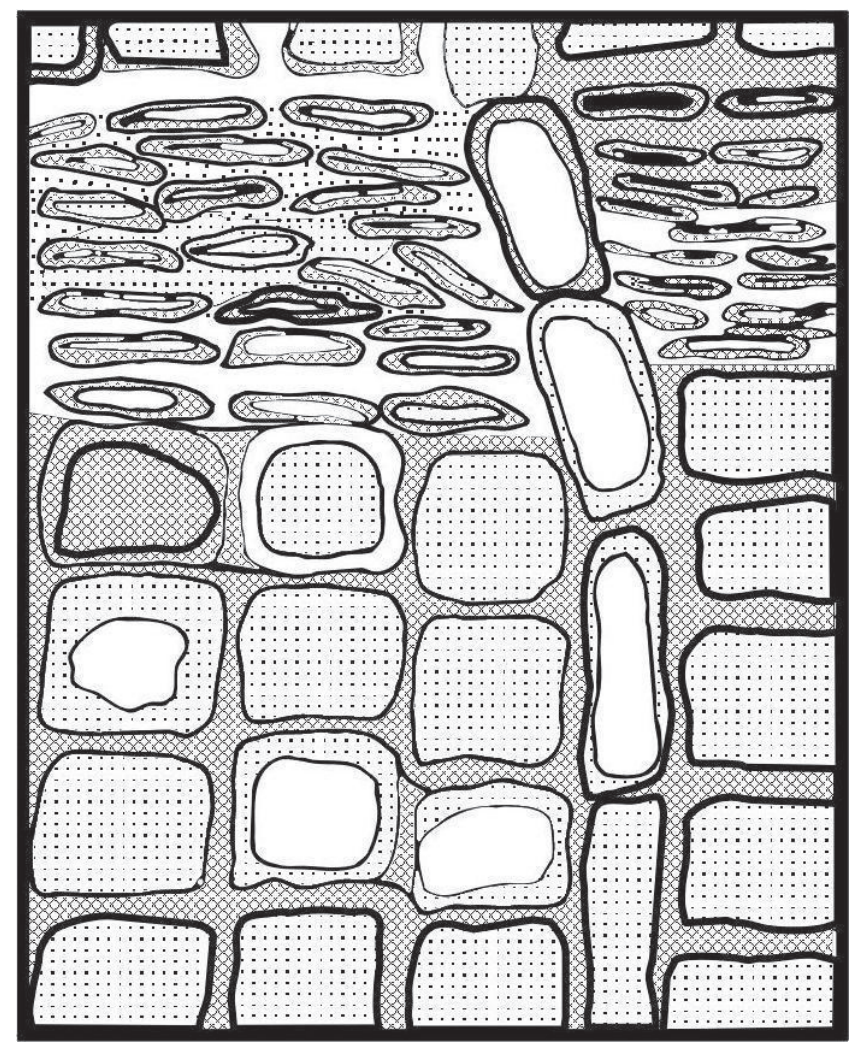

Figura 3. Secção transversal ilustrando a entrada e a precipitação de minerais no estágio 2. Alguns lumens celulares estão preenchidos e outros não. Em algumas células ocorre a precipitação de minerais na superfície interna das paredes celulares (ver legenda da Figura 7).

Figure 3. Cross-section showing the entrance and mineral precipitation in stage 2. Some cellular lumens are filled out and other not. In some cells was observed the mineral precipitation in the inner surface of the cellular walls (see legend of the Figure 7). 


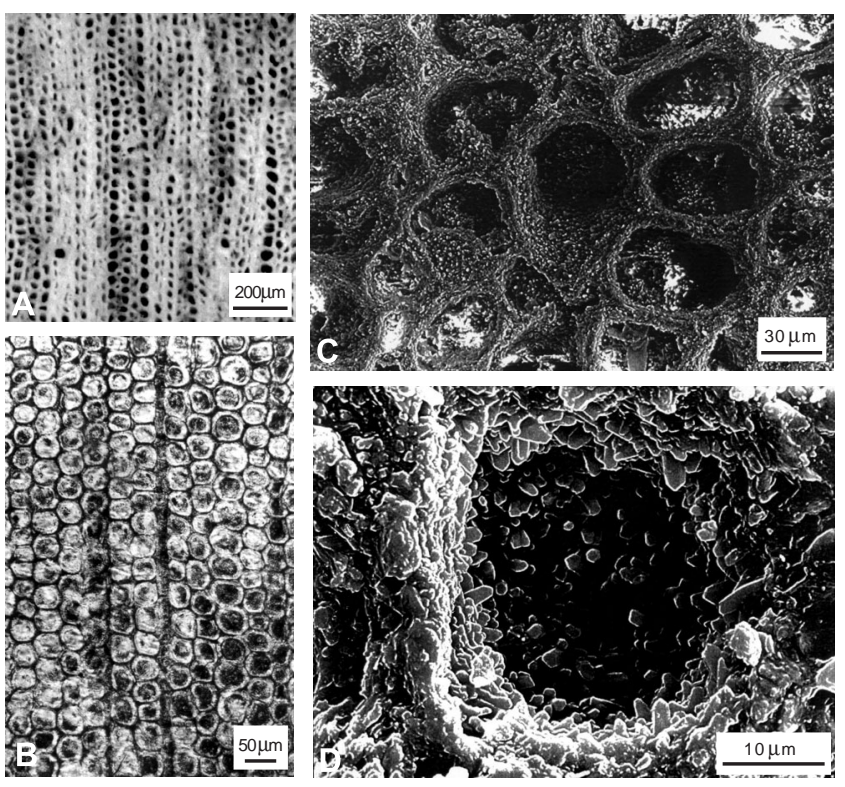

Figura 4. A. Células em secção transversal com a parede bem definida e o interior vazio, isto é, não mineralizado (MOE, amostra $\mathrm{Pb}-030$ ); B. Células com parede e lúmen celular bem definido (MOT, amostra $\mathrm{Pb}-788$ ); C, D. Células em secção transversal mostrando a precipitação de minerais na superfície da parede (MEV, amostra $\mathrm{Pb}-067)$; D. Detalhe da Figura C, as paredes celulares apresentam microquartzo com sentido de crescimento em direção à região central da célula.

Figure 4. A. Cross-section cells with well-defined wall, but empty, non-mineralized interior (SOM, sample $\mathrm{Pb}-030$ ); B. Cells with welldefined wall and lumen (TOM, sample Pb-788); C, D. Cross-section cells showing the mineral precipitation in the wall surface (SEM, sample $\mathrm{Pb}-067)$; $\mathbf{D}$. Detail of the Figure $\mathrm{C}$, cellular walls with microquartz growing in direction to the central area of the cell.

modificação diagenética, comumente, a opala-A é transformada em opala-CT e, posteriormente, em quartzo. Esta transformação é uma reação de dissolução e re-precipitação (Carson, 1991).

Nas células em que não ocorreu o preenchimento dos lumens, as paredes apresentam geralmente microquartzo $(<10$ $\mu \mathrm{m})$. O microquartzo da parede apresenta cristais de terminações subédricas e sentido de crescimento em direção a região central da célula (Figura 4D). Na face interna, os cristais apresentam terminações piramidais subédricas. Quando o lúmen celular foi preenchido, em geral, está ocupado por cristais piramidais de microquartzo anédricos a subédricos.

Buurman (1972) observou que as madeiras opalizadas apresentavam excelente preservação das estruturas celulares e que a representação desta estruturas diminuía com o aumento de quartzo no exemplar. Conforme Mussa \& Coimbra (1984), as texturas criptocristalina e microcristalina do quartzo tendem a romper mais os tecidos do que as texturas médias e grosseiras. Bolzon \& Oliveira (2000) também evidenciaram esta relação em caules fósseis do Cenozóico da região de Uruguaiana, Rio Grande do Sul.

Os processos de silicificação do lenho estariam relacionados, principalmente, aos ambientes de clima quente (Buurman, 1972) ou subtropical (Koeniguer, 1987) e com alternâncias de estações (Beauchamp, 1981), com inverno úmido- quente e verão seco (Carson, 1991). As soluções contendo sílica seriam formadas durante as estações úmidas pela dissolução de aluminosilicatos ou argilominerais e, nos períodos secos, a evaporação poderia concentrar as soluções e favorecer a precipitação de minerais silicatados (Silvério da Silva et al., 1997).

\section{Alterações na parede celular com a degradação de elementos orgânicos residuais}

Os processos diagenéticos relacionados aos elementos orgânicos residuais (Figura 5) dificilmente são observados em microscopia ótica ou eletrônica. Constituem exemplos deste estágio, as áreas do tecido lenhoso definidas como células “fantasmas" (Bolzon, 1993; Bolzon \& Machado, 2002), isto é, quando não é possível determinar os limites da parede celular e dos lumens (Figura 6). As evidências também estão relacionadas, principalmente, com quebras do tecido lenhoso que seguem as orientações das estruturas anatômicas. Por outro lado, os elementos orgânicos residuais podem ser encontrados em análises geoquímicas orgânicas (Sigleo, 1978, 1979; Bolzon, 1993).

A degradação de elementos orgânicos residuais do lenho mineralizado estaria relacionada com as mudanças no ambiente diagenético. Os elementos orgânicos derivados principalmente da lignina que ficaram no interior do tecido lenhoso podem ser removidos ou submetidos ao aquecimen-

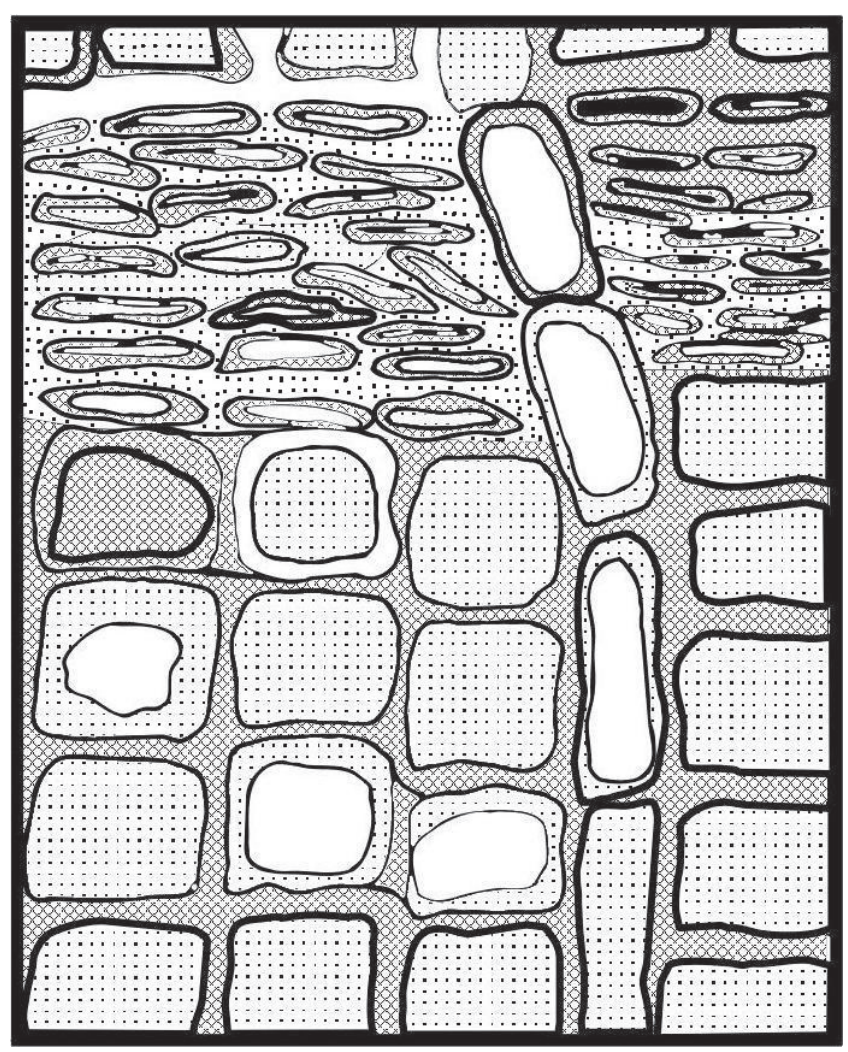

Figura 5. Secção transversal ilustrando o estágio 3 , com as alterações na parede celular e o início da degradação dos elementos orgânicos residuais (ver legenda da Figura 7).

Figure 5. Cross-section showing stage 3 , with cellular walls altered and the beginning of residual organic elements degradation (see legend of the Figure 7). 


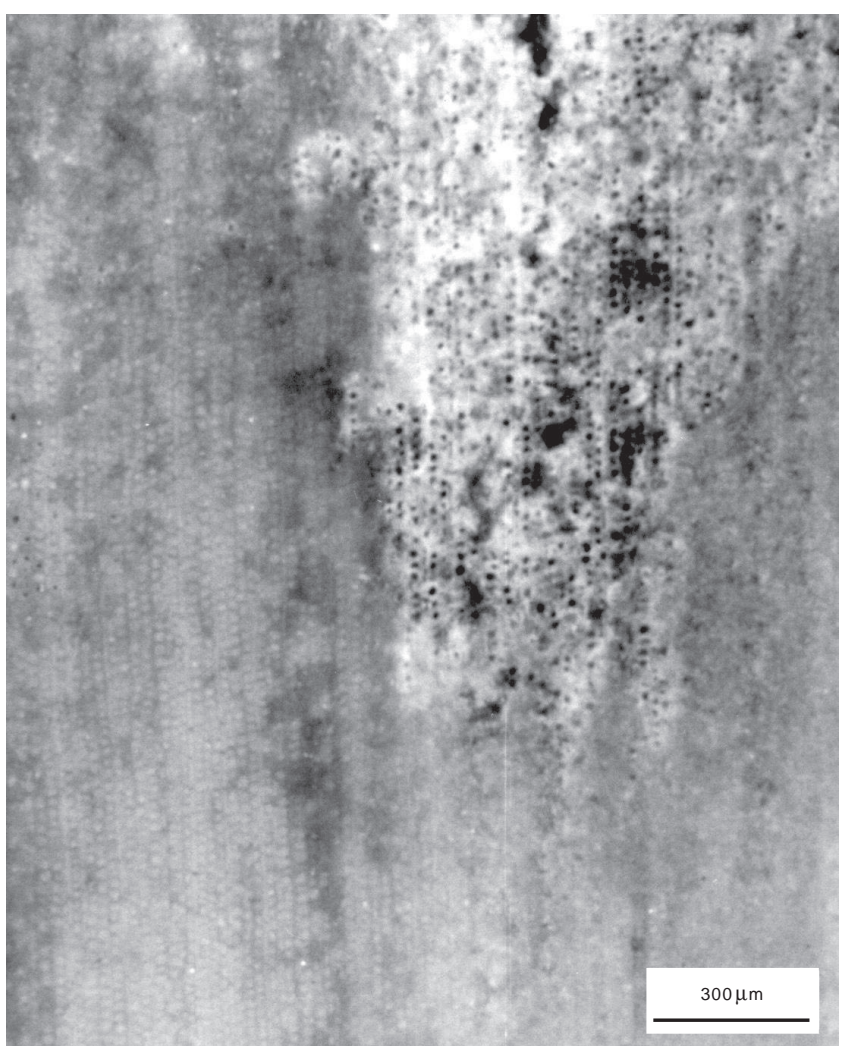

Figura 6. Preservação em mosaico com células onde não é possível definir a parede e o lúmen ("fantasma"), e outras onde os limites são evidentes (MOE, amostra $\mathrm{Pb}-037$ ).

Figure 6. Mosaic cell preservation without defined wall and lumen ("ghost"), and another where the limits are evident (SOM, sample $\mathrm{Pb}-037)$.

to geotérmico. A remoção poderia ocorrer por ação intempérica (Mussa \& Coimbra, 1984), por exposição ao oxigênio atmosférico (Sigleo, 1979), por oxidação pelo retorno de águas ácidas ou pelo aquecimento resultante de intrusões de diabásio (Schopf, 1971). De acordo com Silvério da Silva et al. (2002), são comuns os diques de diabásio discordantes em rochas sedimentares triássicas na borda da Bacia do Paraná, no Estado do Rio Grande do Sul. Os processos geotérmicos que ocorrem devido à carga de sedimento acumulado durante o processo de sedimentação e subsidência tornam os elementos residuais da lignina altamente estáveis (Sigleo, 1978).

\section{Preenchimento e/ou precipitação de minerais a partir da superfície dos lumens celulares}

Este estágio diagenético compreende a principal fase de destruição do tecido lenhoso (Figura 7). Os espaços surgidos pela remoção dos elementos orgânicos constituem um molde celular interno. O preenchimento deste molde, para alguns autores, corresponde à recristalização (Mussa \& Coimbra, 1984). Schopf (1971) propôs que os elementos-traço de matéria orgânica poderiam contribuir no estágio de recristalização. Segundo Bolzon (1993), a recristalização pode ocorrer em condições ambientais semelhantes aos processos iniciais de mineralização. Neste caso, o tecido lenhoso seria destruído formando uma região "amorfa” (Figura 8A).
Por outro lado, o tecido lenhoso poderia ser reconhecido quando as diferenças físicas e químicas entre os minerais do lúmen e da parede celular indicariam outra etapa de mineralização (Figura 8B, C, D), na qual as características físicas (porosidade, fraturas) e químicas ( $\mathrm{pH}$ e Eh) seriam mais importantes que as bioquímicas (organização do tecido e composição da parede celular).

Os processos relacionados a esta etapa ocasionaram a formação de cristais com baixo grau de perfeição das faces nas paredes celulares. Nestas, as regiões medianas (lamela média) possuem cristais com faces bem desenvolvidas e com formação superficial de protocristais. Também ocasionaram áreas do lenho com células reconhecidas apenas pelas variações na morfologia dos cristais (Figuras 8B, C) e com as paredes das células adjacentes apresentando microquartzo lamelar e muitas vezes, cristais subédricos com faces parcialmente desenvolvidas.

Também nessa etapa, são incluídas as células que apresentam óxidos férricos associados às regiões de fratura ou na região mais externa do exemplar, e que estariam associadas com a destruição do tecido lenhoso (Figura 8D). A relação dos hidróxidos férricos com o processo de silicificação é ainda incerta. Os íons férricos são observados, preferencialmente, nas paredes celulares e, raramente, nos lumens. Conforme

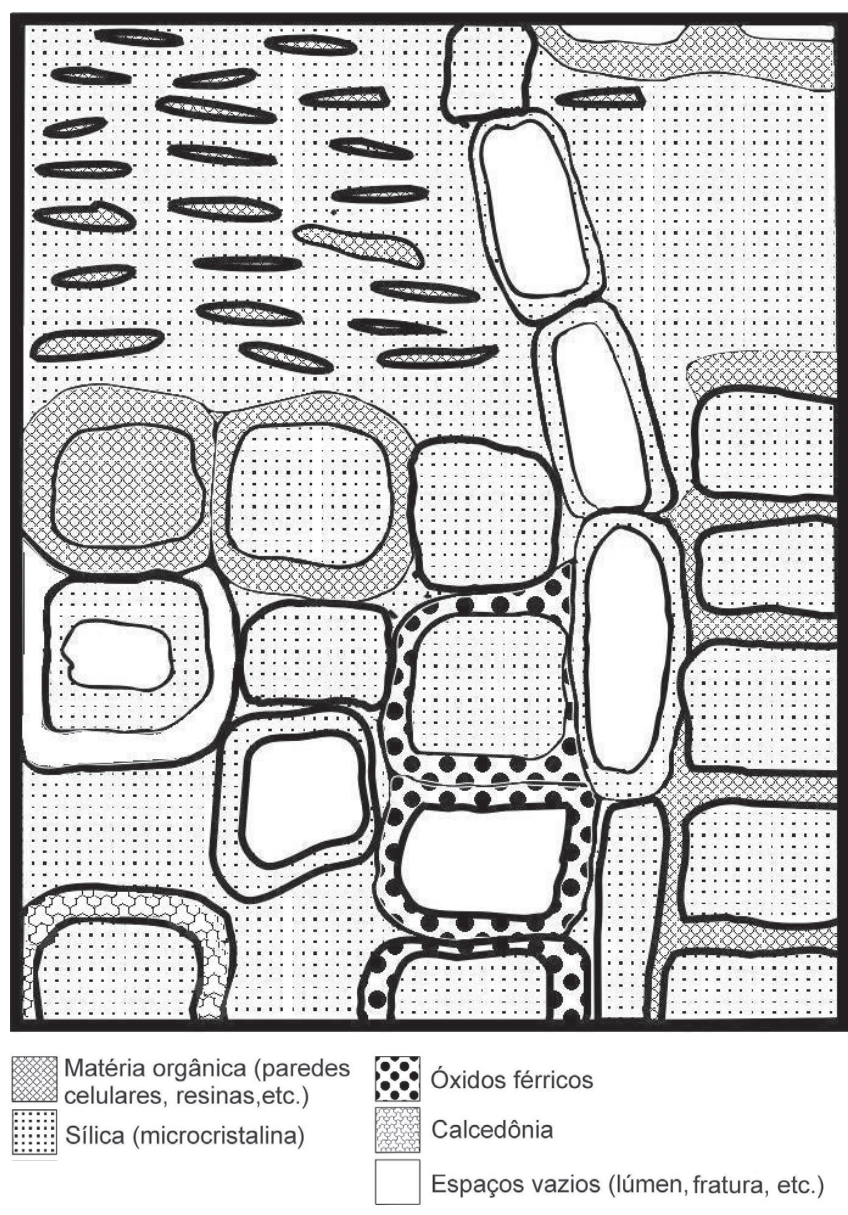

Figura 7. Secção transversal ilustrando a destruição do tecido lenhoso no estágio 4 e a preservação em mosaico.

Figure 7. Cross-section showing the wood destruction and the mosaic preservation in stage 4 . 
Beauchamp (1981), os íons férricos se fixam sob a forma de hematita e podem evoluir para goetita. Sigleo (1979) propôs a co-precipitação do ferro com a sílica, ou que a sua presença poderia acelerar a nucleação de precipitados de sílica. Nos lenhos do Mesozóico do Rio Grande do Sul, os óxidos são freqüentemente encontrados nas regiões mais externas dos exemplares e em áreas mais internas, próximas a fraturas.

Ainda são incluídas neste estágio diagenético as fraturas dos lenhos silicificados que não seguem a estrutura da anatomia do tecido lenhoso (Figura 8E). Estas fraturas podem ser ocasionadas por acomodações do terreno ou outros processos físicos. As áreas de fraturas do lenho podem ocorrer preenchidas com cristais de quartzo romboédricos quase euédricos, ou por megaquartzo subédricos (Figura 8F). Observou-se que, a partir de um mesmo cristal, ocorreu nucleação de vários outros em diferentes regiões de uma mesma amostra.

\section{CONSIDERAÇÕES FINAIS}

A análise dos processos diagenéticos ocorridos nos lenhos Mesozóicos do Rio Grande do Sul possibilitou o esta- belecimento de um modelo. Este modelo inclui quatro principais estágios.

A dissolução e a degradação progressiva dos constituintes da parede celular parecem estar acompanhadas da consolidação dos minerais, sendo mantida a estabilidade dimensional das estruturas. Neste estágio teria ocorrido o colapso e as torções de células. A sílica entrou e precipitou, inicialmente, na forma de opala, nas superfícies internas da parede celular. Em algumas células, a sílica preencheu completamente o lúmen. As condições anóxicas e o pH ácido condizem com as condições de degradação do tecido lenhoso.

Após o primeiro estágio, as células do tecido lenhoso provavelmente não foram modificadas em sua morfologia. A maioria das estruturas celulares foi destruída por processos relacionados com alterações na parede celular e com a degradação de elementos orgânicos residuais, com o subseqüiente preenchimento e/ou precipitação de minerais, a partir da superfície dos lumens celulares. A intensidade desta destruição está relacionada com o tipo e a textura da sílica e dos outros minerais eventualmente associados.

A opala teria evoluído para a forma de quartzo microcristalino
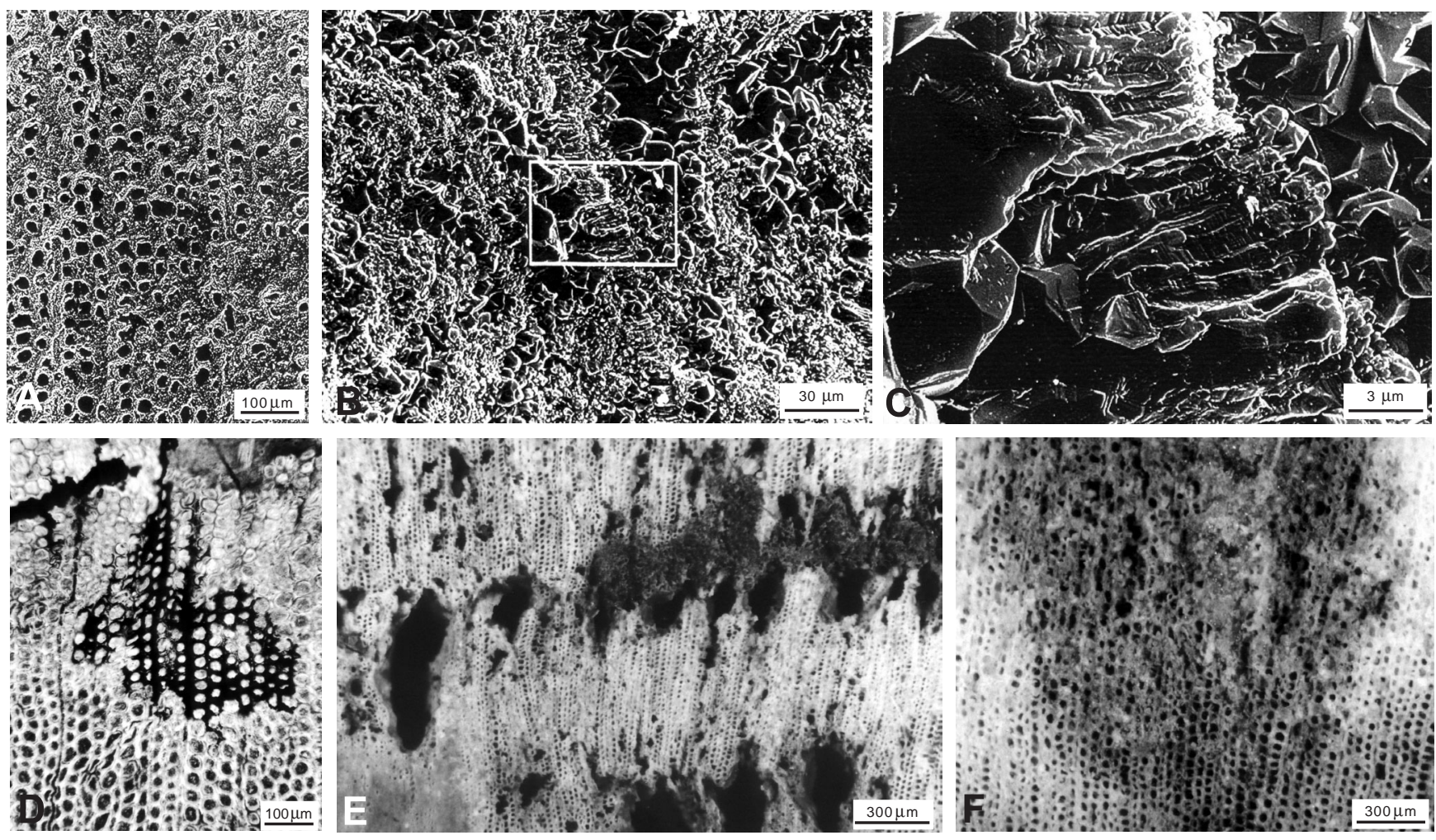

Figura 8. A. Preservação em mosaico: regiões de células com a parede e o lúmen preservados ocorrem com regiões amorfas (ausência de células), onde a mineralização destruiu as estruturas celulares (MEV, amostra Pb-067); B, C. Paredes de células com variações na morfologia dos cristais: na parede, cristais lamelares; no lúmen, cristais subédricos (MEV, amostra Pb-067); C. Detalhe da Figura B; D. Células com óxidos férricos (ao centro) associadas às regiões de fraturas, regiões amorfas e com células bem definidas (MOT, amostra $\mathrm{Pb}-788) ; \mathrm{E}$. Secção transversal mostrando a porosidade relacionada com fraturas não preenchidas e regiões com tecido lenhoso destruído (MOE, amostra Pb-030); F. Fratura de lenho (ao centro) com cristais de megaquartzo (MOE, amostra Pb-030).

Figure 8. A. Mosaic preservation: areas of cells with preserved wall and lumen associated with amorphous areas (absence of cells), where the mineralization destroyed the cellular structures (MEV, sample Pb-067); B, C. Wall cells with variations in the morphology of the crystals: lamellar crystals in the wall and sub-hedrics crystals in the lumen (MEV, sample Pb-067); C. Detail of the Figure B; $\mathbf{D}$. Cells with ferric oxides (center) associated to the areas of fractures, amorphous areas and well-defined cells (TOM, sample Pb-788); E. Crosssection showing cavities related with fractures filled out and areas with cells of the destroyed wood (SOM, sample Pb-030); F. Wood fractures (center) with megaquartz crystals (SOM, sample $\mathrm{Pb}-030)$. 
nos lumens celulares ou de calcedônia nas paredes celulares. Os centros de cristalização da calcedônia seriam os lumens de células adjacentes. Cristais de megaquartzo ocorrem em fraturas e em regiões onde o tecido lenhoso foi destruído.

Os estágios principais de alteração das estruturas celulares ocorreram em alguns caules ao longo de diferentes intervalos de tempo, enquanto que em outros exemplares foram contemporâneos. Cada estágio determinou uma preservação distinta do tecido lenhoso e, ao mesmo tempo, a sua destruição. Nos caules em que estes estágios foram contemporâneos, o tecido lenhoso apresenta-se como um mosaico de células com diferentes categorias de preservação.

\section{AGRADECIMENTOS}

Os autores agradecem ao Departamento de Paleontologia e Estratigrafia da UFRGS, ao Museu Guido Burgomanero, Departamento de Geologia da UFPR, ao Departamento de Geociências da UFSM e ao CNPq pelo auxílio financeiro recebido (proc. 420111/00-9 - Laboratório de Paleobotânica, BANPESQUFPR 94003786). Também a Inês Azevedo, pela leitura crítica do trabalho e pela contribuição na elaboração das figuras que ilustram os estágios de preservação dos lenhos.

\section{REFERÊNCIAS}

Beauchamp, J. 1981. Structure et mode de silicification de quelques bois fossiles. Sciences Geológiques Bulletin, 34(1):13-20.

Bolzon, R.T. 1993. A lignitafoflora mesozóica do Rio Grande do Sul (Brasil): métodos de estudo e considerações sobre tafonomia, paleoecologia e paleoclimatologia. Curso de Pós Graduação em Geociências, Universidade Federal do Rio Grande do Sul, Dissertação de Mestrado, 142 p.

Bolzon, R.T. \& Guerra-Sommer, M. 1994. Considerações sobre a tafonomia da lignitafoflora mesozóica do Rio Grande do Sul. Acta Geológica Leopoldensia, 17(39):93-107.

Bolzon, R.T. \& Machado, L.G. 2002. Lignitafoflora mesozóica da região de São Pedro do Sul e Faxinal do Soturno: estimativa da preservação celular. Paleontologia em Destaque, 40:19-20.

Bolzon, R.T. \& Marchiori, J.N.C. 1993. Alterações morfoanatômicas resultantes de processos tafonômicos ocorridos em madeiras fósseis do mesozóico do Rio Grande do Sul (Brasil). In: CONGRESSO BRASILEIRO DE PALEONTOLOGIA, 13, 1993. Boletim de Resumos, São Leopoldo, SBP, p. 38.

Bolzon, R.T. \& Oliveira, É.V. 2000. Associação de lenhos fósseis da região de Uruguaiana, Estado do Rio Grande do Sul, Brasil: considerações sobre geologia e tafonomia. Revista da Universidade de Guarulhos (Geociências), 5:160-163.

Bolzon, R.T.; Silvério da Silva, J.L. \& Costa Junior, M.I. 1994. Madeiras silicificadas e sedimentos associados do Mesozóico do Rio Grande do Sul, Brasil. In: REUNIÃO DE PALINÓLOGOS E PALEOBOTÂNICOS, 8, 1994. Noticias, Buenos Aires, ALPP, 11(2):33.

Buurman, P. 1972. Mineralization of fossil wood. Scripta Geologica, 12:1-43.

Carson, G.A. 1991. Silicification of fossils. In: P.A. Allison \& D.E.G. Briggs (eds.) Taphonomy. Nova Iorque, Plenum, p. 455-499.

Faccini, U.F. 1989. O Pemo-Triássico do Rio Grande do Sul. Curso de Pós-Graduação em Geociências, Universidade Federal do Rio Grande do Sul, Dissertação de Mestrado, 121 p.
Guerra-Sommer, M. \& Gamermann, N. 1985. Mineralogia de troncos fósseis da região de São Pedro do Sul, Triássico, Rio Grande do Sul. In: CONGRESSO BRASILEIRO DE PALEONTOLOGIA, 7, Salvador, 1983. Série Geologia, Rio de Janeiro, DNPM, 27(2):587-603.

Kim, Y.S. \& Sing, A.P. 2000. Micromorphological characteristics of wood biodegradation in wet environments: a review. IAWA Journal, 21(2):135-155.

Koeniguer, J.C. 1987. Paléoécologie de quelques gisements a végétaux fossiles du Bassin Parisien. Bulletin d'Information des Geologues du Bassin de Paris, 24(2):23-32.

Leo, R.F. \& Barghoorn, E.S. 1976. Silicification of wood. Harvard University Botanical Museum Leaflets, 25:1-47.

Morey, P.R. 1980. O crescimento das árvores. $1^{\mathrm{a}}$ ed. São Paulo, EDUSP, $72 \mathrm{p}$.

Mussa, D. \& Coimbra, A.M. 1984. Método de estudo tafonômico aplicado a lignispécimes permianos da bacia do Paraná. Anais da Academia Brasileira de Ciências, 56(1):85-101.

Myelan, B.A. \& Butterfield, B.G. 1972. Three dimensional structure of wood - a scanning electron microscope study. $1^{\mathrm{a}}$ ed. Hong Kong, Chapman \& Hall, 80 p.

Obst, J.R.; McMillan, N.J.; Blanchette, R.A.; Christensen, D.J.; Faix, O.; Han, J.S.; Kuster, T.A.; Landucci, L.L.; Newman, R.H.; Pettersen, R.C.; Schwandt, V.H. \& Wesolowski, M.F. 1991. Caracterization of Canadian Artic fossil woods. Bulletin of the Geological Survey of Canada, 403:123-146.

Scherer, C.M.S.; Faccini, U.F. \& Lavina, E.L. 2000. Arcabouço estratigráfico do Mesozóico da bacia do Paraná. In: M. Holz, \& L.F. De Ros (eds.) Geologia do Rio Grande do Sul,Editora da UFRGS, p. 335-374.

Schopf, J.M. 1971. Notes on plant tissue preservation and mineralization in a Permian deposit of peat from Antarctica. Americam Journal of Science, 271:522-543.

Schopf, J.M. 1975. Modes of fossil preservation. Review of Palaeobotany and Palynology, 20:27-53.

Schweingruber, F.H. 1982. Microscopic wood anatomy. $2^{\mathrm{a}}$ ed. Teufen, F. Flück-Wirth, $226 \mathrm{p}$.

Sigleo, A.C. 1978. Organic geochemistry of silicified wood, Petrified Forest National Park, Arizona. Geochimica et Cosmochimica Acta, 42:1397-1405.

Sigleo, A.C. 1979. Geochemistry of silicified wood and associated sediments, Petrified Forest National Park, Arizona. Chemical Geology, 26:151-163.

Silvério da Silva, J.S. 1997. Estudo dos processos de silicificação e calcificação em rochas sedimentares mesozóicas do Rio Grande do Sul, Brasil. Programa de Pós-Graduação em Geociências, Universidade Federal do Rio Grande do Sul, Tese de Doutorado, 157 p.

Silvério da Silva, J.S. \& Bolzon, R.T. 1997. Electron microscopy of silicified wood of São Pedro do Sul, Rio Grande do Sul, Brazil. Revista da Universidade de Guarulhos (Geociências), 2:231.

Silvério da Silva, J.S.; Menegotto, E. \& Bolzon, R.T. 1997. Quartz crystallinity index of silicified woods of Rio Grande do Sul State, Brazil. In: CONGRESSO BRASILEIRO DE PALEONTOLOGIA, 15, 1997. Resumos, Rio Claro, SBP, p. 36.

Silvério da Silva, J.L.; Hirata, R.C.A.; Flores, E.L. \& Dressler, V.L. 2002. Novas hipóteses sobre a origem do flúor no Sistema Aqüífero Guarani na Depressão Central Gaúcha, Brasil. In: CONGRESSO BRASILEIRO DE ÁGUAS SUBTERRÂNEAS, 13, 2002. CD-ROM, Florianópolis, p. 20.

Taylor, T.N. \& Taylor, E.L. 1993. The biology and evolution of fossil plants. $1^{\mathrm{a}}$ ed. New Jersey, Pratice Hall, $982 \mathrm{p}$. 